\title{
CYTOTOXIC ACTIVITY OF A BLACK BEAN (PHASEOLUS VULGARIS L.) EXTRACT AND ITS FLAVONOID FRACTION IN BOTH IN VITRO AND IN VIVO MODELS OF LYMPHOMA
}

Ulises Aregueta-Robles ${ }^{1 \neq}$, Oscar R. Fajardo-Ramírez ${ }^{1 \neq}$, Luis VillelaA ${ }^{1,2 *}$, Janet A. Gutiérrez-Urib ${ }^{3 / 4}$

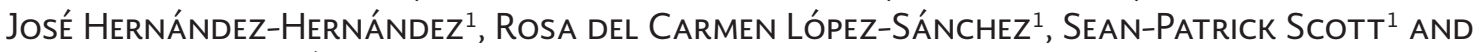
Sergio Serna-SALdívar ${ }^{3}$

${ }^{1}$ Tecnológico de Monterrey, Escuela de Medicina y Ciencias de la Salud, Monterrey, N.L.; ${ }^{2}$ Instituto de Seguridad y Servicios Sociales de los Trabajadores del Estado de Sonora (ISSSTESON), Centro Médico Dr. Ignacio Chávez, Hermosillo, Son.; ${ }^{3}$ Tecnológico de Monterrey, Centro de Biotecnología-FEMSA, Monterrey, N.L.; ${ }^{4}$ Tecnológico de Monterrey, Pueb́la, Puebla, Mexico

\section{ABSTRACT}

Background: Black bean (Phaseolus vulgaris L.) is a very common legume seed in Mexican diet. Flavonoids and crude extracts from different plants have been reported as effective agents for chemoprevention and cytotoxicity in several cancer cell lines. We investigated the effects of black bean hulls extract (BBE) and its flavonoid fraction (FF) on lymphoma cells. Methods: BBE and FF were characterized by high-performance liquid chromatography. Viability and flow cytometry assays were carried out. Finally, a mouse model was generated to test the in vivo effect of both fractions. Results: Both BBE and FF inhibited cell prolife ation in a dose-dependent way. In addition, cells underwent apoptosis, and the cellular population at S-phase increased after expossure to these fractions. Furthermore, mice treated with BBE or FF increased the overall survival by 5 or 6 days, respectively, in comparison with a placebo group $(p=0.056$. Discussion: BBE and FF had cytotoxic action by driving OCI-Ly7 cells into apoptosis as well as blocking progression to $\mathrm{G} 2 / \mathrm{M}$ phase. In addition, $\mathrm{BBE}$ and FF treatments were effective in xenograft models.

Key words: Flavonoids. Black bean extract. Lymphoma. Phaseolus vulgaris.

\section{INTRODUCTION}

Diffuse large-B-cell lymphoma (DLBCL) is the most common type of non-Hodgkin's lymphoma ( $\mathrm{NHL}$ ) in

Corresponding author:

*Luis Villela

Escuela de Medicina y Ciencias de la Salud,

Tecnológico de Monterrey

Edificio CITES, 3er piso

Av. Morones Prieto No. 3000 Poniente

Col. Los Doctores

C.P. 64710, Monterrey, N.L., México

E-mail: Villela@itesm.mx adults, representing $30-40 \%$ of all cases ${ }^{1}$. In Mexico, lymphoma is the third and fourth cause of death in males and females of economically productive age (25-45 years), respectively².
${ }^{\ddagger}$ Both authors contributed equally.

Received for publication: 06-09-2017

Approved for publication: 06-12-2017 doi: 10.24875/RIC.17002395 
With respect to survival rates (SR) for this entity, the initial response to treatment is a key factor. Patients with partial response or refractoriness to cyclophosphamide, hydroxydaunorubicin, vincristine (oncovin) and prednisone (CHOP) had a short SR (median: 10 months) ${ }^{3}$. In patients receiving treatment regimens with the monoclonal antibody rituximab (R-CHOP), the SR increased by $10 \%{ }^{4}$. Therefore, research of new therapeutic molecules to improve the initial response and, consequently, the SR is mandatory.

Several drugs obtained from natural sources have been added to chemotherapy schemes of DLBCL. Vincristine, a molecule isolated from an endemic plant of Madagascar named Madagascar periwinkle (Catharanthus roseus), is currently used to treat leukemia and Hodgkin's lymphoma, among other tumors. Another molecule, doxorubicin, was obtained from Streptomyces peucetyus and is part of regimens for breast cancer, leukemia, and lymphomas 5 . In this context, several reports have suggested that diet-derived phenolic compounds may have potential antineoplastic effects by reversing, inhibiting or delaying tumor development ${ }^{6}$. Black bean (Phaseolus vulgaris L.), a commonly consumed seed in the Mexican diet, is extremely rich in flavonoids, polyphenols, tannins, saponins, phytosterols, and other antioxidants ${ }^{7}$. Some studies have reported that the black bean hulls extract (BBE) is a protective agent against chemically-induced DNA damage in bone marrow and peripheral blood cells in vivo ${ }^{8}$, as well as providing protection against colon carcinogenesis in mice. Its cytotoxic effect has been tested in several tumor cell lines such as breast (MCF-7), hepatic (HepG2), colon $\left(\mathrm{CaCO}_{2}\right)$, and cervix $(\mathrm{HeLa})^{7,10}$.

Several authors have fractioned the BBE to isolate its molecules and characterize its antineoplastic properties. One study showed that the saponin-rich fraction of BBE stimulates the immune system against cancer cells ${ }^{11,12}$. Black bean tannins inhibited cellular proliferation of colon, prostate, and breast cell lines ${ }^{13,14}$. In addition, flavonoid fractions (FF) and flavonoid single molecules inhibited cell growth and triggered apoptosis in human prostate cancer cells (PC-3) $)^{15}$, as well as having proapoptotic effects against CCRF-CEM, Daudi, HeLa and lung adenocarcinoma cell lines ${ }^{16-18}$.

In this study, we investigated the cytotoxic effect of methanolic BBE and its flavonoids fraction against the aggressive lymphoma cell line. In addition, we evaluated their potential apoptotic effect in vitro as well as their capability to disrupt the cell cycle. Then, we tested their effect on a xenograft model and compared with placebo and cyclophosphamide (used as reference control) by oral administration.

\section{MATERIALS AND METHODS}

\section{Preparation of the BBE and FF}

The BBE was prepared as described by Gutiérez-Uribe et al. ${ }^{10}$, whereas the FF was obtained by dissolving $2 \mathrm{~g}$ of dried BBE in $20 \mathrm{~mL}$ of methanol (DEQ Monterrey, Mexico) followed by sonication (Branson ${ }^{\circledR} 85 \frac{\circ}{10}$ ) for $5 \mathrm{~min}$, then $20 \mathrm{~mL}$ of tri-distilled water was added and homogenized by sonication for 5 more $\mathrm{min}$. The blend was centrifuged at $800 \mathrm{~g}$ for 5 min (Centrifuge Allegra and Beckman Coulter ${ }^{\circledR}$ ) and the supeinatant was recovered. The flavonoids were purified using a $C_{18}$ Solid Phase Extraction cartridge $20 \mathrm{cc} / 5 \mathrm{~g}$ (Waters ${ }^{\circledR}$, Milford, and MA) followed by a washing step with $10 \mathrm{~mL}$ of $25 \% \mathrm{MeOH}$, and the flavonoid-rich fraction was recovered by eluting $10 \mathrm{~mL}$ of $60 \% \mathrm{MeO}$. The flavonoid solution was then dried by lyophilization (Freezone Benchtop 20.5 L, Labconco ${ }^{\oplus}$ ).

\section{High-performance liquid chromatography (HPLC) identification and quantification of flavonoids}

Both BBE and FF were analyzed according to the procedure described by Guajardo et al. ${ }^{19}$. Briefty, the extracts (BBE or FF) were dissolved in $80 \%$ methanol to a concentration of $1 \mathrm{mg} / \mathrm{mL}$ before their injection into the HPLC system. HPLC analysis was achieved with gradient elution using $(A)$ water adjusted to $\mathrm{pH} 2$ with trifluoroacetic acid (Sigma, St. Louis, MO), and (B) HPLC-grade acetonitrile (Merck, Darmstadt, Germany) as the mobile phase at a flow rate of $0.5 \mathrm{~mL} / \mathrm{min}$. The column employed was Zorbax SB-Aq $4.6 \times 1 \overline{50} \mathrm{~mm}$ and $3.5 \mu \mathrm{m}$ (Agilent, USA). Fractionation was achieved with gradient conditions at room temperatureas follows: $20 \% \mathrm{~B}$ for the first $6 \mathrm{~min}$, increasing the $\mathrm{B}$ concentration to $50 \%$ at $12 \mathrm{~min}$ and to $100 \%$ at $30 \mathrm{~min}$. At the end of the chromatographic separation initial conditions were reacquired to achieve accurate equilibration of the column. The injection volume was $5 \mu \mathrm{L}$ 
of either BBE or FF. Each chromatogram was recorded at $360 \mathrm{~nm}$ (bandwidth-16) and $280 \mathrm{~nm}$. BBE and FF compounds were analyzed with HPLC LC/MSD-TOF (Agilent Technologies, Waldbrunn, Germany) to confirm the identity of flavonoids. On both analyses, standards of myricetin, quercetin, and kaempferol (Sigma, St. Louis, MO) were used to quantify the flavonoids present in the BBE and the FF as reported previously ${ }^{10,19}$.

\section{Cell culture}

The DLBCL-derived cell line (OCl-Ly7) was kindly provided by Professor Ricardo Dalla Favera from Columbia University, (New York, NY). NIH-3T3 and VERO cells were obtained from ATCC (CRL-1658 and CCL-81). Cells were cultured in IMDM, (Invitrogen, Carlsbad, CA) supplemented with $10 \%$ fetal bovine serum, (Invitrogen, Carlsbad, CA), 1\% pen-strep; and maintained at $37^{\circ} \mathrm{C}$ in $5 \%$ of $\mathrm{CO}_{2}$ atmosphere.

\section{Cytotoxicity assays}

OCl-Ly7 cells were cultured in a white opaque 96-well plate (Corning, Pittston, PA), at a density of $2 \times 10^{4}$ cells/well. Cells were exposed to different concentrations of BBE, FF or CTX ( $90 \%$ pure per USP reference standards, Laboratorios Sanfer S.A. De C.V., Mexico), used as positive control. After $24 \mathrm{~h}$, cellular viability was monitored using CellTiter-Blue reagent (Promega, Madison, WI). To evaluate the effect over normal cells, NIH-3T3 and VERO cell lines were exposed to the extracts under the same conditions.

\section{Apoptosis and cell cycle assay}

Cells were plated in a 12-well plate (Costar, Wilkes Barren, PA) at a density of $2 \times 10^{5}$ cells/well and exposed to either BBE or FF using the $\mathrm{IC}_{50}$ obtained in the cytotoxicity assays. Following an incubation of $24 \mathrm{~h}$, cells were trypsinized and washed with cold phosphate-buffered saline (PBS); the number of apoptotic cells was determined using the annexin $\mathrm{V}$ (AV)-FITC/PI apoptosis assay kit (Miltenyi Biotech, Auburn, CA). A minimum of $1 \times$ $10^{4}$ events was recorded using FACS Canto ${ }^{\mathrm{TM}}$ II system (BD, San Jose, $C A$ ). Fluorescence intensities for both AF and $\mathrm{PI}$ were obtained and analyzed in FACSDiva software (BD Biosciences). Double positive ( $\mathrm{AF}$ and $\mathrm{PI}$ ) or single positive (AF) were set as apoptotic cells. For the cêtl cycle analysis, the Cell CycleTEST ${ }^{\text {w" }}$ plus DNA reagent ${ }^{2}$ it BD (San Jose, $C A$ ) was used. A total of $1 \times 10^{4}$ events were captured and histograms of PI fluorescence intensity were used to determine the distribution of cells in three major phases within the cycle ( $G 1$ vs. S vs. G2/Mi). The percentage of cells in each cycle was determined using the ModFit LT 3.2, Verity Software House (Topsham, $\mathrm{ME})$. All experiments were run in triplicate.

\section{Mice strain and housing conditions}

The protocol was approved by the Institutional Committee for laboratory animal welfare of the Escuela de Medicina y Ciencias de la Salud at Tecnológico de Monterrey (approval 2010-011, September 07, 2010), and the animals were treated under institutionat guidelines for the care and use of animals. Male C.B-17/IcrHsdPrkdc SCID mice, 6-8 weeks old, were obtained from Harlan Laboratories Inc., (Indianapolis, IN) and boused at sterile conditions in the clean room conditioned with positive pressure air flow at the vivarium of the Escuela de Medicina y Ciencias de la Salud at Tecnológico de Monterrey. Environmental conditions were: $21^{\circ}{ }^{\circ} \mathrm{C} \pm 2{ }^{\circ} \mathrm{C}$ and $55 \% \pm 15 \%$ relative humidity and light/darleycles of $12 \mathrm{~h}$. Mice were held individually in sterile ye hitilated cages (Tecniplast, Italy). Before the experiments, mice were kept under standard animal housing conditions for 2 weeks with free access to sterile water and food (Global 19\% Protein Extruded Rodent Diet, - Teklad Diets, Madison, WI). Sterile water was supplemented with trimethoprim and sulfamethoxazole as a prophylactic antibiotic as part of the protocol for avgiding opportunistic infections. At the end of the experimental protocol, animals used as negative controls underwent anesthesia and euthanasia with a mixture of Ketamine (100 mg/mL, Laboratorios Aranda, Qro, Mexiç) and Xylacine $(20 \mathrm{mg} / \mathrm{mL}, 25 \mathrm{~mL}$ Laboratorios Aranđa, Qro, Mexico). The doses were $200 \mathrm{mg}$ of ketamine and $16 \mathrm{mg}$ of xylacine per $\mathrm{kg}$ of body weight administered into the anterolateral region of any caudal limb muscle, followed by cervical dislocation once the mice presented absence of motor reflexes and periorbital signs.

\section{Xenografting model and treatment}

To generate the animal model, a suspension $\mathrm{af}$ lymphoma cells $\left(1 \times 10^{7}\right.$ cells suspended in $300 \mu \mathrm{L}$ of 
media) was administrated intraperitoneally as previously described by Schimdt et al. ${ }^{20}$. Cells used for injection were maintained in log phase with viability around $98 \%$. The animal model for lymphoma was characterized by histopathological analysis using hematoxylin and eosin staining, along with immunohistochemistry for CD79a and BCL-6 to confirm the tumor type. Following the characterizations, mice underwent treatment and were divided into four groups: The placebo group which received only PBS, one group receiving the FF (15 mg/mouse/day, using the rodent pellets as the vehicle), another group receiving the BBE (20 mg/mouse/day, using the rodent pellets as the vehicle), and the control group which received CTX (i.p. At $150 \mathrm{mg} / \mathrm{kg}$ of body weight); the administration schedule was one injection every 3 days for a total of 7 applications ${ }^{21}$. Body weight and mice behavior were monitored during the experiment. After animal death, tumors were extracted and underwent pathological analysis. The survival time was registered since tumor implantation.

\section{Statistical analysis}

Matlab ${ }^{\circledR} 2010$ software was used for the statistical analysis. All in vitro assays were performed in triplicate reporting data as a mean and standard deviation. $I C_{50}$ was calculated by a variation of the Hill equation ${ }^{22}$. For apoptosis and cell cycle, statistical differences were assessed using the two-tailed $t$-test to test the null hypothesis of no difference between populations. The differences between tumor volumes and weights were evaluated through ANOVA analyses. In the animal model, statistical differences between treatments from Kaplan-Meier curves were evaluated using the log-rank test (SPSS Statistics 19 was used in this test). $p \leq 0.05$ was considered significant.

\section{RESULTS}

\section{Characterizations of flavonoids content}

The chromatographic analysis of FF identified three glycosylated flavonoids: myricetin 3-O-glucoside at a concentration of $11.29 \mathrm{mg} / \mathrm{g}$, while quercetin 3-O galactoside and kaempferol 3-O glucoside were present at concentrations of 97.68 and $1.00 \mathrm{mg} / \mathrm{g}$, respectively ${ }^{19,23}$.

\section{Cytotoxic properties}

BBE showed a dose-dependent cytotoxic effect on a culture of OCl-Ly7 with a $\mathrm{a}_{0}$ calculated $I_{50}$ of $0.131 \pm 0.004 \mathrm{mg} / \mathrm{mL}$. A similar response was observed in cells exposed to the $\mathrm{FF}$ ( $\mathrm{IC}_{50:} 0.154 \pm 0.007 \mathrm{mg} / \mathrm{mL}$ ), while the $\mathrm{IC}_{50}$ for $\mathrm{CTX}$ was $0.745 \pm 0.035 \mathrm{mg} / \mathrm{mL}$, showing that both fractions (BBE and FF) were more cytotoxic than $\mathrm{CTX}$ $(p<0.0005)$ (Fig. 1).

Specificity for tumor cells is one of the most-wanted characteristics in drugs for cancer therapy; therefore, we exposed non-cancer cells ( $\mathrm{NIH}-3 \mathrm{~T} 3$ and VERO) to our extracts. For this purpose, we used a high concentration of BBE ( $1 \mathrm{mg} / \mathrm{mL})$, and the percentages of living cells were $95.31 \% \pm 6.38 \%$ and $90.17 \% \pm 7.33 \%$ in NIH-3T3 and VERO cells, respectively, both being highly different to the viability found in $\mathrm{OCl}-\mathrm{L} \& 7$ cells $(1.17 \% \pm 0.18)$. Regarding the FF, with a final concentration of $1.32 \mathrm{mg} / \mathrm{mL}$, the viabilities observed were $65.74 \% \pm 10.25 \%$ and $80.42 \% \pm 4.36 \%$ in NIIH- 3 T3 and VERO cells, respectively. These results showed that the tumor cells tend to be significantly more sensitive to the fractions obtained from black bean than non-cancer cells.

\section{Flow cytometry assay}

After exposing the tumor cells to BBE using the $\mathrm{IC}_{50}$ obtained in cytotoxicity assays, we observed that $41.6 \%$ of cells were positive for both $\mathrm{AV}$, a molecule expressed in cell surface during early stages ofapoptosis, and propidium iodide (PI), a molecule that binds DNA in cells with damaged membranes or late stage of apoptosis (Fig. 2B). While $44.6 \%$ were positive for both markers in the cells exposed to FF (Fig. 2C), only $7.4 \%$ of cells were $\mathrm{AV}$ and $\mathrm{PI}$ positive when they were exposed to the vehicle (PBS) (Fig. 2A) $(p<0.0001$ and $p<0.001$, respectively) almost similar was observed in cells exposed to cyclophensphamide (CTX) (Fig. 2D).

\section{Cell cycle analysis}

Regarding the cell cycle stages, the normal distribution of log phase OCl-Ly7 cells (treated with vehicle) was $24.51 \% \pm 0.63 \%$ in $\mathrm{G} 1,65.16 \% \pm 0.88 \%$ in $\mathrm{S}$, 
Figure 1. Cell viability assays. OCl-Ly7 cells were exposed to several concentrations of either black beans hulls extract flavonoid fraction (FF), cyclophosphamide (CTX), or Vehicle (DMSO) for $24 \mathrm{~h}$.

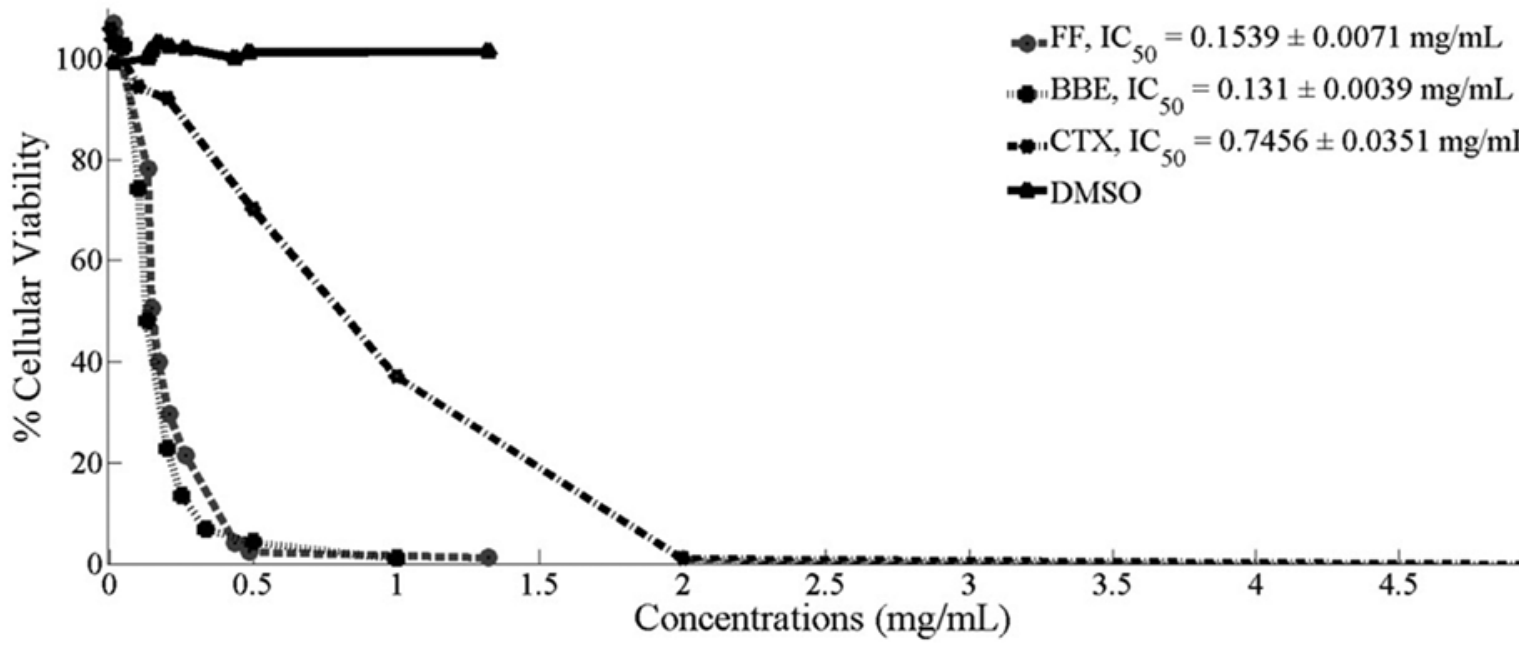

and $10.33 \% \pm 1.23 \%$ in G2/M (Fig. 2E). The addition of BBE to the cell culture changed the distribution to $21.4 \% \pm 0.91 \%$ in $\mathrm{G} 1,77.15 \% \pm 0.93 \%$ in $\mathrm{S}$, and $1.53 \% \pm 0.88 \%$ in G2/M (Fig. 2F), while in the cells exposed to $\mathrm{FF}$, the distribution was $21.5 \% \pm 0.82 \%$ in $\mathrm{G} 1,77.91 \% \pm 0.87 \%$ in $\mathrm{S}$, and $0.59 \% \pm 0.27 \%$ in G2/M (Fig. 2G). Interestingly, the treatment with CTX resulted in similar distributions in $\mathrm{G} 1$ and $\mathrm{S}$ phases ( $21.69 \% \pm 0.76 \%$ and $62.62 \% \pm 0.52 \%$, respectively) compared to control, but more cells ( $15.4 \% \pm 0.43 \%$ ) were arrested in G2/M (Fig. 2H).

\section{In vivo analysis of cytotoxicity}

All inoculated mice presented characteristics of tumor growth in nodes compared to non-inoculated mice. Histopathological analysis confirmed that neoplastic tissue corresponded to diffuse proliferation of large lymphocytes showing positive nuclear expression of $\mathrm{BCL}-6$ and positive membrane expression for CD79a (Fig. 3A-C). Interestingly, oral administration of either BBE or FF increased the SR compared with the group of mice treated with placebo $(p=0.056)$; surprisingly, the response was similar to the group treated with CTX (Fig. 4). The SR for the $\mathrm{FF}$ group was 33.3 days (confidence interval [Cl]: 95\%: 28.1-38.5), while for BBE and CTX were 33.8 (Cl 95\%: 28.3-39.5) and 33.1 (Cl 95\%: 28.4-37.8) days, respectively. The SR in the placebo group was 26.7 days ( $\mathrm{Cl}$ 95\%: 23.7-29.8).

\section{DISCUSSION}

DLBCL represents the most common subtype of $\mathrm{NHL}$, accounting for $30-40 \%$ of all newly diagnosed-cases. In the United States, 8000 deaths per year are caused by this disease. The current therapeutic schemes for $\mathrm{NHL}$ include the administration of doxorubicin and vincristine, two molecules obtained from natural sou

In this respect, $60 \%$ of all approved anticance $\frac{\overline{\mathrm{P}}}{\mathrm{e}}$ drugs in the USA during 2010, were obtained from hatural sources ${ }^{24}$. It is well-known that natural dietary compounds have chemoprevention effects by blocking, inhibiting, reversing, or retarding the process of carcinogenesis. In this context, BBE has been widely used for its antineoplastic properties ${ }^{8}$. The phytochemical content (tannins, flavonoids, saponins, and phytosterols) of this extract has been linked to the inhibition of proliferation of cancer cells and the scavenging of free radicals ${ }^{7}$.

In this study, chromatographic analysis of the FF o $\bar{b}$ tained from the BBE of $P$. vulgaris L., identified three mofecules (myricetin 3-O glucoside, quercetin 3-O glucoside, and kaempferol 3-O glucoside). In this context, Cheing et al. described an FF from Gynostemma pentaphyllum composed of 8 molecules, two of them quercetin derivatives, and showed a cytotoxic effect over prostate cancer cell line $(P C-3)^{15}$. Furthermore, Jeganathan et al. reported the same three flavonols contained in Camellia sinensis L. (Myricetin 3-O glucoside, Quercetin 3-O glucoside, and Kaempferol 3-O glucoside), in a wideły used 
Figure 2. Flow cytometry analysis. Apoptosis results (Annexin-V/PI) of cells exposed to vehicle (A), to black beans hulls extract $(B B E)(B)$, to flavonoid fraction (FF) (C), and cyclophosphamide (CTX). In addition, DNA content was analyzed in cells treated with vehicle (E), BBE (F), FF (G), and CTX (H).

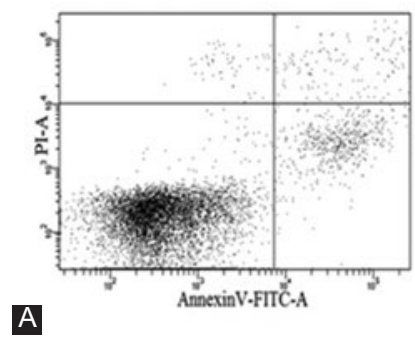

A
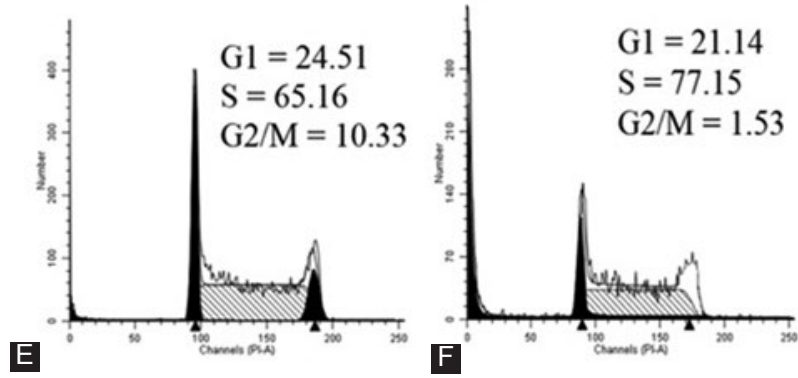

Figure 3. Characterization of the in vivo model. (A) Hematoxylin and Eosin staining of the tumor excised from mice injected with the OCl-Ly7 cell suspension resulted in a classical aggressive non-Hodgkin's lymphoma cell population. In addition, both nuclear expression of positive BCL-6 (B) and membrane expression of CD79a (C) were detected.

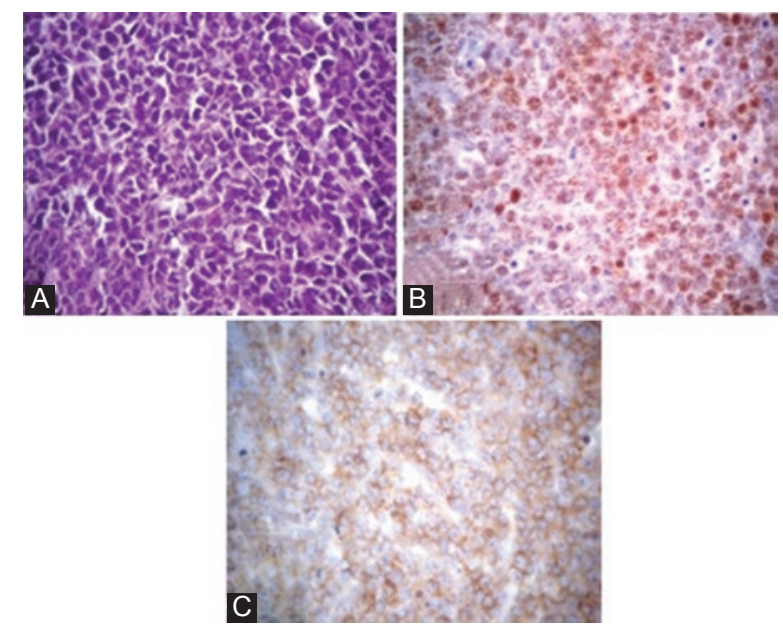

tea plant (C. sinensis L.) from Sri Lanka but at different concentrations $(0.94 \mathrm{mg} / \mathrm{g}, 1.5 \mathrm{mg} / \mathrm{g}$, and $1.31 \mathrm{mg} / \mathrm{g}$, respectively ${ }^{25}$; this plant has been reported to have antioxidant, antimicrobial, anticancer, anti-atherosclerotic, and anti-proliferative properties.

In this study, we describe the anti-proliferative effect of both BBE and FF over a lymphoma cell line (OCI-Ly7) in a dose-dependent manner. In addition, we found that

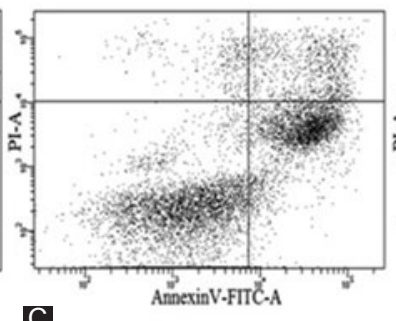

C

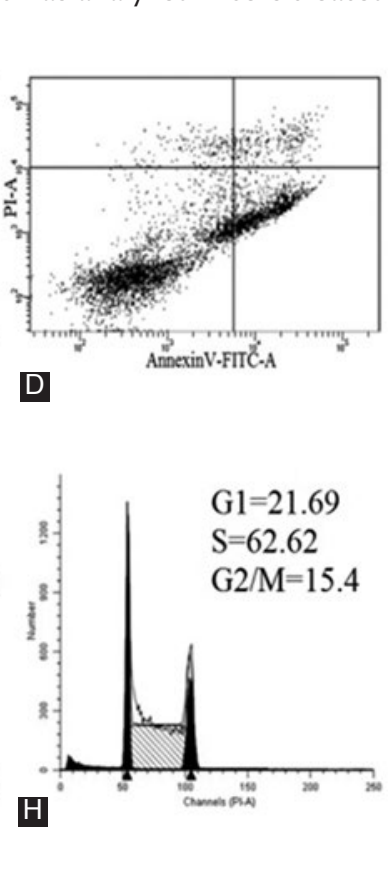

both FF and BBE were capable of inducing apoptosis and arresting the cell cycle in S-phase, which also süggests that the glycosylated flavonoids from BBE were responsible for its effect. In terms of selectivity, our experiments demonstrated that the tumor cell line was moresensitive to both extracts than non-cancer cells (Nif- $-3 T 3$ and VERO), which can be explained by the growth rate of tumor cells compared with non-cancer cells.

The results of cytotoxicity assays using the $\mathrm{BBE}$ and FF were similar to other studies. For instance,cthe FF obtained from Rhus verniciflua Stokes induced apoptosis in B-cell lymphoma (BJAB) and T-cell lym homa (Jurkat) ${ }^{26}$. A similar apoptotic effect and arzest of G2/M phase in human $B$ lymphoma cells ( $B J A B$ ) were observed by other researchers using the same component at $100 \mu \mathrm{g} / \mathrm{mL}^{27}$.

Regarding the cell cycle arrest, our results suggest that both treatments (BBE and FF) blocked the entrance to the $\mathrm{G} 2 / \mathrm{M}$ phase since an increase in duration of the $S$ phase was observed. In this context, Cheng et at. published that both flavonoids and saponins obtained from Gynostemma pentaphyllum were capable of inducing apoptosis and arresting in $\mathrm{S}$ and $\mathrm{G} 2 / \mathrm{M}$ phases in prostate cancer cells $(P C-3)^{15}$. In addition, they found that both fractions modulated the expression of cycin $\mathrm{A}, \mathrm{a}$ molecule part of the complex needed for this transition 
Figure 4. Kaplan-Meier lymphoma survival curves. Survival population was plotted since day 20 after inoculation and 1 day before the first subject decease was reported. Statistical differences between groups were calculated using chi-square test according to the log-rank test. Black beans hulls extract (BBE) group and flavonoid fraction (FF) group were not statistically different from CTX group, with $p$ values of 0.42 and 0.8 , respectively. All treated groups, BBE, FF, and CTX, obtained a trend $p=0.056$.

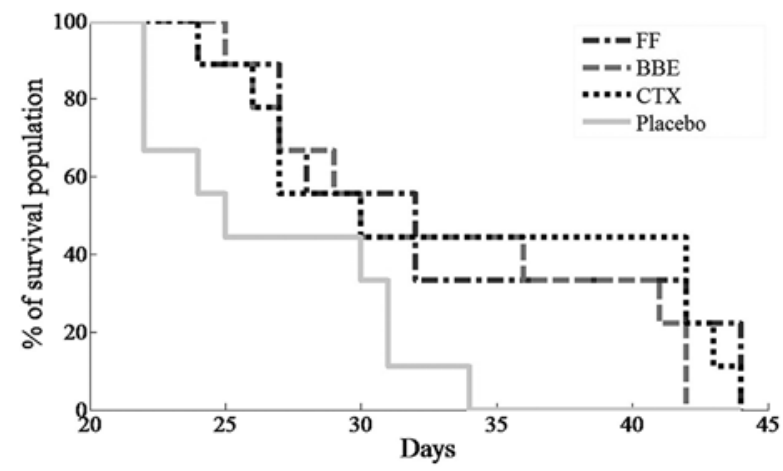

(cyclin-A/cdk2)28 and the expression of caspase-3, which is an important key in the apoptotic process.

To test the effect of these fractions in vivo, we developed a xenografting model and assessed it using histological analysis. The results of biopsies taken from the grafted mice showed positive cells for CD79a and BCL-6 (two commonly used markers for DLBCL). With the animal model well characterized, the group of mice under placebo treatment died around day 26.7, while the group under CTX treatment (150 mg/kg i.p.) died days later (33.1 days), which showed the expected outcome. Surprisingly, the cytotoxic effect observed in vitro was observed in vivo as well, since the groups of mice receiving BBE or FF survived around 33.3 and 33.8 days, respectively.

In addition, oral administration through food is an advantage and a straightforward way of treatment using these fractions. A similar observation was reported using either alkaloid or terpenoid fractions administered in the food of mice grafted with either lymphoma (DAL) or lung cancer cells (L-929); in this study, the fractions increased the SR around $35.64 \pm 1.05$ days and a reduction in tumor volume were observed ${ }^{29}$.

Data showed in our study addresses new questions about the components in both BBE and FF, specifically, the effect of the sugar residue on the glycoside forms isolated from this plant, and the outcome of different concentrations and/or ratios among the flavonoids.
Finally, in this study, we found that both BBE and FF from $P$. vulgaris L. Had cytotoxic properties comparable to cyclophosphamide, a widely-used molecule for cancer therapy. In addition, these extracts seemed to be specific for tumor cells, since they were almost innocuous to non-cancer cells ( $\mathrm{NIH}-3 \mathrm{~T} 3$ and VERO cells). Another important observation was that the administration of the extracts in a xenografting model of lymphoma increased the SR, similar to that was observed with cyclophosphamide treatment. Further studies are needed to identify specific components of the fractions that exhibited the observed cyfotoxic properties. For example, Oncamex, the myricetin-derived flavonoid, has shown antitumor activity ina preclinical model ${ }^{30}$.

\section{ACKNOWLEDGMENTS}

The authors thank Qiong Shen for providing the cells donated by Prof. Dalla Favera, and to Maríaulsabel García Cruz for laboratory administrative and technical assistance. This study was supported by Gátedra de Hematología y Cáncer and Research Chair Funds and NutriOmics Research Group from Tecnø̈lógico de Monterrey, and by Consejo Nacional de Ciencia y Tecnología (CONACYT, Mexico) via student scholarship no. 39331.

\section{REFERENCES}

1. Ahmedin-Jemal DV, Bray F, Center MM, Jacques-Feplay ME, Ward E, Forman D. Global cancer statistics. CA Cancer J Clin. 2011;61:69-90.

2. Meneses-García A, Ruiz-Godoy L, Beltrán-Orțega A, Sánchez-Cervantes F, Tapia-Conyer R, Mohar A. Principales neoplasias malignas en México y su distribución geográfica. Rev Invest Clin. 2012;64:322-9.

3. Villela L, López-Guillermo A, Montoto S, et al. Prognosstic features and outcome in patients with diffuse large B-cell lymphoma who do not achieve a complete response to first-line regimens. Cancer. 2001;91:1557-62.

4. Coiffier B, Thieblemont C, Van Den Neste E, et al. Long-term outcome of patients in the $\mathrm{LNH}-98.5$ trial, the first randomized study comparing rituximab-CHOP to standard $\mathrm{CHO}$ - chemotherapy in DLBCL patients: a study by the groupe d'etudes des lymphomes de l'adulte. Blood. 2010;116:2040-5.

5. Zhang Z, Yu X, Wang Z, Wu P, Huang J. Anthracyclines potentiate anti-tumor immunity: a new opportunity for chemoimmunotherapy. Cancer Lett. 2015;369:331-5.

6. Kris-Etherton PM, Hecker KD, Bonanome A, et al. Bioactive compounds in foods: their role in the prevention of cardioyascular disease and cancer. Am J Med. 2002;113 Suppl 9B:71S-88S.

7. Aparicio-Fernández X, Reynoso-Camacho R, Castaño-TOstado E, et al. Antiradical capacity and induction of apoptosis on HeLa cells by a Phaseolus vulgaris extract. Plant Foods Hum Nutr. 2008;63:35-40. 
8. Azevedo L, Gomes JC, Stringheta PC, et al. Black bean (Phaseolus vulgaris L.) as a protective agent against DNA damage in mice. Food Chem Toxicol. 2003;41:1671-6.

9. Bobe G, Barrett KG, Mentor-Marcel RA, et al. Dietary cooked navy beans and their fractions attenuate colon carcinogenesis in azoxymethane-induced ob/ob mice. Nutr Cancer. 2008;60: 373-81.

10. Gutiérrez-Uribe JA, Serna-Saldívar SR, Moreno-Cuevas JE, Hernández-Brenes C, Guajardo-Touché EM. Cancer Cell Growth Inhibition by Black Bean (Phaseolus vulgaris L.) Extracts. United States Patent US No. 2006024394/A1; 2006.

11. Berhow MA, Wagner ED, Vaughn SF, Plewa MJ. Characterization and antimutagenic activity of soybean saponins. Mutat Res. 2000;448:11-22

12. Shi J, Arunasalam K, Yeung D, et al. Saponins from edible legumes: chemistry, processing, and health benefits. J Med Food. 2004;7:67-78.

13. Bawadi HA, Bansode RR, Trappey A $2^{\text {nd }}$, Truax RE, Losso JN. Inhibition of caco-2 colon, MCF-7 and hs578T breast, and DU 145 prostatic cancer cell proliferation by water-soluble black bean condensed tannins. Cancer Lett. 2005;218:153-62.

14. Kandil FE, Smith MA, Rogers RB, et al. Composition of a chemopreventive proanthocyanidin-rich fraction from cranberry fruits responsible for the inhibition of 12-O-tetradecanoyl phorbol-13-acetate (TPA)-induced ornithine decarboxylase (ODC) activity. J Agric Food Chem. 2002;50:1063-9.

15. Cheng TC, Lu JF, Wang JS, et al. Antiproliferation effect and apoptosis mechanism of prostate cancer cell PC -3 by flavonoids and saponins prepared from Gynostemma pentaphyllum. J Agric Food Chem. 2011;59:11319-29.

16. Ferguson PJ, Kurowska E, Freeman DJ, Chambers AF, Koropatnick DJ. A flavonoid fraction from cranberry extract inhibits proliferation of human tumor cell lines. J Nutr. 2004;134: 1529-35.

17. Kameswaran TR, Ramanibai R. The antiproliferative activity of flavonoidal fraction of Indigofera tinctoria is through cell cycle arrest and apoptotic pathway in A-549 Cells. J Biol Sci. 2008;8:584-90.

18. Son YO, Lee KY, Lee JC, et al. Selective antiproliferative and apoptotic effects of flavonoids purified from Rhus verniciflua stokes on normal versus transformed hepatic cell lines. Toxicol Lett. 2005;155:115-25.
19. Guajardo-Flores D, García-Patiño M, Serna-Guerrero D, Gutiérrez-Uribe JA, Serna-Saldívar SO. Characterizatjon and quantification of saponins and flavonoids in sprouts, seed coats and cotyledons of germinated black beans. Food Chem. 2012;134:1312-9.

20. Schimdt-Wolf IG, Negrin RS, Kiem HP, Blume KG, Weissman IL. Use of a SCID mouse/human lymphoma model to evaluate cytokine-induce killer cells with potent antitumor cell activity. J Exp Med. 1991;174:139-49.

21. Man S, Bocci G, Francia G, et al. Antitumor effects in mice of lowdose (metronomic) cyclophosphamide administered continuously through the drinking water. Cancer Res. 2002;62:2731 $\overline{5}$.

22. Goutelle $S$, Maurin M, Rougier F, et al. The hill equation; a review of its capabilities in pharmacological modelling. Fundam Clin Pharmacol. 2008;22:633-48.

23. Guajardo-Flores D, Serna-Saldívar SO, Gutiérrez-Úpibe JA. Evaluation of the antioxidant and proliferative activities of extracted saponins and flavonols from germinated black beans (Phaseolus vulgaris L.). Food Chem. 2013;141:1497-503.

24. Newman DJ, Cragg GM. Natural products as sources- of new drugs over the 30 years from 1981 to 2010. ] Nat Prod. 2012;75:311-35.

25. Jeganathan B, Punyasiri PA, Kottawa-Arachchi JD, et at Genetic variation of flavonols quercetin, myricetin, and kaempferol in the Sri Lankan tea (Camellia sinensis L.) and their health-promoting aspects. Int J Food Sci. 2016;2016:6057434.

26. Lee JC, Lee KY, Kim J, et al. Extract from Rhus verniciflua stokes is capable of inhibiting the growth of human lymphoma cells. Food Chem Toxicol. 2004;42:1383-8.

27. Jang HS, Kook SH, Son YO, et al. Flavonoids purified from Rhus verniciflua stokes actively inhibit cell growth and induce apoptosis in human osteosarcoma cells. Biochim Biophys Acta. 2005;1726:309-16

28. Pagano M, Pepperkok R, Verde F, Ansorge W, Draetta G. Cyclin $A$ is required at two points in the human cell cycle EMBO J. 1992;11:961-71.

29. Chitra V, Sharma S, Kayande N. Evaluation of anticancer activity of Vitex negundo in experimental animals: an in vitro and in vivo study. Int J Pharm Tech Res. 2009;1:1485-9.

30. Martínez-Pérez C, Ward C, Turnbull AK, et al. Antitumoractivity of the novel flavonoid on camex in preclinical breast cancer models. Br J Cancer. 2016;114:905-16. 